\title{
Knowledge, Attitude and Behavior of Health Care Workers in the Prevention of COVID-19
}

Shokofeh Maleki

Kermanshah University of Medical Sciences

Farid Najafi

Kermanshah University of Medical Sciences

Khosro Farhadi

Kermanshah University of Medical Sciences

Mahmoud Fakhri

Kermanshah University of Medical Sciences

Fatemeh Hosseini

Kermanshah University of Medical Sciences

Mehdi Naderi ( $\nabla$ m.naderi51@yahoo.com)

Kermanshah University of Medical Sciences https://orcid.org/0000-0002-5608-6582

Research article

Keywords: knowledge, attitude, behavior, practice, health care workers, COVID-19

Posted Date: April 25th, 2020

DOI: https://doi.org/10.21203/rs.3.rs-23113/v1

License: (c) (i) This work is licensed under a Creative Commons Attribution 4.0 International License. Read Full License 


\section{Abstract}

Background Preserving the health of health care workers (HCWs) has now become one of the main concerns of all countries affected by the coronavirus. Maintaining the health of the hospital workers, especially the medical staff, requires knowledge and awareness, followed by proper behavior for disease prevention and transmission. The purpose of this study was to evaluate the knowledge, attitude and behavior of HCWs to ward patients with suspected or confirmed COVID-19.

Methods A cross-sectional study was designed to assess the level of knowledge, attitude and behavior of $191 \mathrm{HCWs}$ of Taleghani Hospital in Kermanshah toward patients with suspected or confirmed COVID-19. Responses to the checklists of demographic characteristics, knowledge, attitude, and behavior toward patients with COVID-19 were analyzed by SPSS 22.

Results 191 subjects (118 females and 73 males) with a mean age of $34.7 \pm 8.6$ years participated in this study. The level of knowledge of HCWs in this study was excellent regarding the ways of transmitting the disease such as close contact with the patient with suspected Coronavirus ( $99 \%$ ). According to their positions, participants had a significant difference in their knowledge of asymptomatic patients $(P<0.001)$. The study found that $14 \%$ of the HCWs did not have the necessary knowledge about the symptoms of COVID-19, indicating poor knowledge of the HCWs at the beginning of the disease epidemic. The results obtained from the evaluation of HCWs attitudes showed that some workers believed that protective and preventive measures should only be applied when managing people with severe symptoms $(P<0.001)$. Finally, there was a significant difference in behavior and adherence to protective and preventive measures between the participants when facing patients with severe symptoms and without symptoms of COVID-19 $(P=0.05)$.

Conclusion Knowledge, attitude, and behavior toward COVID-19 infection and facing patients with severe and overt symptoms among health care workers in the hospital were Excellent, but these were insufficient for patients without obvious symptoms. These results suggest that additional training regarding subclinical cases of Coronavirus is needed for HCWs to protect them from contamination and prevent disease transmission to their colleagues and other patients as well.

\section{Introduction}

The highest number of cases of communicable diseases among health care workers is reported at the beginning of each disease period when the disease and its prevention and treatment methods are not yet fully understood and there is no complete knowledge of them [1, 2]. The Coronavirus is the most recently discovered viruses that have caused a new disease called COVID-19.

The Coronavirus Disease 2019 (COVID-19) epidemic began in Wuhan, China in late 2019 and continues to spread globally(1), with exported cases confirmed in 123 countries at the time of writing(2). Corona entered Iran from Feb. 19 to Feb 23, and by Apr 9, nearly 66220people had been infected with the virus.COVID-19 can spread via cough or respiratory droplets, contact with bodily fluids, or from contaminated surfaces(3).Health-care workers are facing an elevated risk of exposure to infectious diseases, including the novel Coronavirus (COVID-19) in all countries. It is imperative to ensure the safety of healthcare workers not only to safeguard continuous patient care but also to ensure they do not transmit the virus (4) as well as another study represented that, infected health care workers were an important group involved in disease spread(5).WHO confirmed 1279722 cases and 72614deaths during the COVID 19outbreak in 2020.

Increasing the level of knowledge and subsequently, proper training of health care workers dealing with patients with suspected or confirmed COVID19 can significantly prevent the development and transmission of disease to other patients and workers. Therefore, hospitals that provide services to patients with suspected or confirmed COVID-19 should increase the level of knowledge of health care workers and provide them with high-level training [8].In addition, preventive measures (such as N95 masks, surgical masks, goggles, and protective clothing) will be useful to ensure the safety of health care workers during COVID-19 outbreaks as well as in the future (6).

Considering the importance of health care for health care personnel in order to prevent any future shortage in providing further care to the patients, we decided to investigate the knowledge, attitude, and behavior of hospital staff towards Coronavirus.

\section{Materials And Methods}

A cross-sectional study was designed to assess the knowledge, attitude and behavior of staff at Taleghani Hospital in Kermanshah toward patients with suspected or confirmed Coronavirus at the beginning of the disease epidemic in Iran on February 27, 2020. For this purpose, a researcher-made checklist based on previous studies [5, 10-11] was used. The checklist examined the areas of knowledge, attitudes, and behavior of health care workers regarding COVID-19. COVID-19 information resources and patients with clinical and subclinical symptoms were evaluated in the area of knowledge, how to take care of yourself as a health care worker and others in the face of suspected patients and the educational needs of health care workers about the emergence of an epidemic of these types of viruses were assessed in the area of attitudes, and ultimately, control and protection practices for health care workers and patients in the transmission of infection were investigated in the area of behavior. All health care workers including physicians, pharmacists, nurses, radiologists, laboratory experts and eligible individuals were included in this study. For the purpose of this study, permanent and non-part time hospital employment with more than six months of hospital work experience who accept to participate were included. If someone respond less than $80 \%$ of the checklist were excluded. In this study, a list of hospital wards was prepared and then according to

Page 2/9 
the percentage of health care workers in each ward, 191 questionnaires were randomly distributed among the HCWs. Statistical analysis was performed using SPSS Version 22. The quantitative variables were described as mean, standard deviation (SD), median, and range of variation depending on the distribution of variables. For the qualitative variables we presented the crude numbers and percentages. In order to compare the knowledge level, attitude, and behavior among health care workers, chi-squared test was used. Significance was determined at the 0.05 threshold.

Ethical permission to conduct the survey was obtained from the Kermanshah University of Medical Sciences, Kermanshah, Iran (approval number IR.KUMS.REC.1399.031) in 2020-03-03.

\section{Results}

The study included 191 health care workers (HCWs) (118 females (61.8\%) and 73 males $38.2 \%)$ with a mean age of $34.7 \pm 8.6$ years. There were 30 (15.7\%) physicians, 65 (34\%)nurses, 7 (3.7\%)radiologists, 10 (5.2\%) operating room technicians, 17 (8.9\%) laboratory experts, 6 (3.1\%) paramedics, and 56 (29.3\%) HCWs working in the administrative department, pharmacy and other hospital departments. Almost the majority of HCWs had heard about Coronavirus (99.5) and knew that it was an acute problem in society in the current situation. About $24.6 \%$ of HCWs took care of or admitted a patient with suspected Coronavirus. $92.1 \%$ of HCWs were worried or somehow feared that the virus would be transmitted to their families or other people. $77 \%$ of HCWs were afraid of being infected with the virus themselves (Table 1). 
Table 1

Socio-demographic characteristics of participants and their awareness about Coronavirus

\begin{tabular}{|c|c|c|c|c|c|c|c|c|}
\hline \multirow[t]{2}{*}{$\begin{array}{l}\text { Socio-demographic } \\
\text { characteristics }\end{array}$} & Physician & Nurse & Radiologist & $\begin{array}{l}\text { Operating room } \\
\text { technician }\end{array}$ & Laboratory expert & Paramedic & Others & \multirow[t]{2}{*}{ Total } \\
\hline & $N(\%)$ & $N(\%)$ & $N(\%)$ & $N(\%)$ & $N(\%)$ & $N(\%)$ & $N(\%)$ & \\
\hline Number & $30(15.7)$ & $65(34)$ & $7(3.7)$ & $10(5.2)$ & $17(8.9)$ & $6(3.1)$ & $56(29.3)$ & 191 \\
\hline \multicolumn{9}{|l|}{ Gender } \\
\hline Female & 16(53.3) & $43(66.2)$ & $6(85.7)$ & $10(100)$ & 12(70.6) & 2(33.3) & $29(51.8)$ & 118(61.8) \\
\hline Male & $14(46.7)$ & $22(33.8)$ & 1(14.3) & - & $5(29.4)$ & $4(66.7)$ & $27(48.2)$ & 73 (38.2) \\
\hline \multicolumn{9}{|l|}{ Work experience } \\
\hline $0-5$ & $22(73.3)$ & $28(43.1)$ & $2(28.6)$ & $2(20)$ & $6(3503)$ & - & $25(44.6)$ & - \\
\hline $5-10$ & $5(16.7)$ & $4(6.2)$ & - & $5(50)$ & - & - & $1(1.8)$ & - \\
\hline $10-15$ & $1(3.3)$ & $16(24.6)$ & $1(14.3)$ & $3(30)$ & $4(23.5)$ & $3(50)$ & 11(19.6) & - \\
\hline Above 15 & $2(6.7)$ & $17(26.2)$ & $4(57.1)$ & - & $7(41.2)$ & $3(50)$ & 19(33.9) & - \\
\hline \multicolumn{9}{|c|}{ Have you heard anything about the Coronavirus? } \\
\hline Yes & 30100) & $64(98.5)$ & $7(100)$ & $10(100)$ & $17(100)$ & $6(100)$ & $56(100)$ & - \\
\hline No & - & $1(1.5)$ & - & - & - & - & - & \\
\hline \multicolumn{9}{|c|}{ Do you think the Coronavirus is an acute problem in society? } \\
\hline Yes & $30(100)$ & $60(92.3)$ & $6(85.7)$ & $10(100)$ & 1588.2) & $4(66)$ & $44(78.6)$ & - \\
\hline No & - & $5(7.7)$ & 1(14.3) & - & 2(11.8) & $2(34)$ & $12(21.4)$ & \\
\hline \multicolumn{9}{|c|}{ Have you encountered a person infected by the Coronavirus while working? } \\
\hline Yes & $17(56.7)$ & $17(26.2)$ & - & $2(20)$ & 2(11.8) & 2(33.3) & $7(12.5)$ & - \\
\hline No & $13(43.3)$ & 48(73.8) & $7(100)$ & $8(80)$ & 15(88.2) & $4(66.7)$ & 49(87.5) & \\
\hline \multicolumn{9}{|c|}{ Have you admitted, cared for, or generally managed the patient suspected of having the Coronavirus? } \\
\hline Yes & 11(36.8) & $10(15.4)$ & - & $2(20)$ & $1(5.9)$ & 2(33.3) & $7(12.5)$ & - \\
\hline No & 19(63.2) & $55(84.6)$ & $7(100)$ & $8(80)$ & 16(94.1) & $4(66.7)$ & $49(87.5)$ & \\
\hline \multicolumn{9}{|c|}{ Are you afraid of getting Coronavirus while working and providing services in the hospital? } \\
\hline Yes & $20(66.7)$ & $51(78.5)$ & $6(85.7)$ & 10(100) & 14(81.3) & $4(66.7)$ & $42(75)$ & - \\
\hline No & $10(33.3)$ & $14(21.5)$ & $1(14.3)$ & - & $3(18.3)$ & 2(33.3) & $14(25)$ & \\
\hline \multicolumn{9}{|c|}{ Are you afraid of transferring the disease from work to family? } \\
\hline Yes & $30(100)$ & $60(92.3)$ & $6(85.7)$ & $10(100)$ & 17(100) & $6(100)$ & 47(83.9) & - \\
\hline No & - & $5(7.7)$ & $1(14.3)$ & - & - & - & $9(16.1)$ & \\
\hline
\end{tabular}

Healthcare Workers; p-values represent the results of the chi-squared test for the null hypothesis of no difference in the Socio-demographic characters

\section{Health care workers' (HCWs) knowledge about Coronavirus}

The level of knowledge of health care workers (HCWs) in this study was excellent (99\%) regarding the ways of transmitting the disease such as close contact with the patient with suspected Coronavirus. About $76.4 \%$ of respondents said patients with suspected Coronavirus or even patients infected by the Coronavirus needed hospitalization. According to their positions, participants had a significant difference in their knowledge of asymptomatic patients $(P<0.001)$. They also knew that people with underlying diseases were more likely to become infected by the virus or even die of the virus (99\%). Fortunately, the majority of participants (93.3\%) were well aware that even a person with mild symptoms could transmit the disease during the incubation period. Further results showed that most of the HCWs (84.8\%) knew that antibiotic use does not affect the prevention and treatment of Coronavirus (Table 2). In this study, $14 \%$ of HCWs were unaware of Coronavirus symptoms. 
Table 2

Health care workers' (HCWs) knowledge about Coronavirus

\begin{tabular}{|c|c|c|c|c|c|c|c|c|}
\hline \multirow[t]{2}{*}{$\begin{array}{l}\text { Knowledge about } \\
\text { Coronavirus }\end{array}$} & Physician & Nurse & Radiologist & $\begin{array}{l}\text { Operating } \\
\text { room } \\
\text { technician }\end{array}$ & $\begin{array}{l}\text { Laboratory } \\
\text { expert }\end{array}$ & Paramedic & Others & \multirow[t]{2}{*}{ p-value } \\
\hline & $N(\%)$ & $N(\%)$ & $N(\%)$ & $N(\%)$ & $N(\%)$ & $N(\%)$ & $N(\%)$ & \\
\hline \multicolumn{9}{|c|}{ Is the Coronavirus transmitted through close contact? } \\
\hline Yes & $30(100)$ & $63(96.6)$ & $7(100)$ & 10(100) & $17(100)$ & $6(100)$ & $56(100)$ & \multirow[t]{2}{*}{-} \\
\hline No & - & $2(3.1)$ & - & - & - & - & - & \\
\hline \multicolumn{9}{|c|}{ Do patients suspected of having the Coronavirus need hospitalization? } \\
\hline Yes & $22(73.3)$ & $47(72.3)$ & $7(100)$ & $10(100)$ & 12(70.6) & $5(83.3)$ & $43(76.8)$ & \multirow[t]{2}{*}{-} \\
\hline No & $8(26.7)$ & 18(27.7) & - & - & $5(29.4)$ & 1(16.7) & 13(23.2) & \\
\hline \multicolumn{9}{|c|}{$\begin{array}{l}\text { Do you have the necessary knowledge of the symptoms of a person with suspected Coronavirus (cough, fever, chills, shortness of breath, and } \\
\text { extreme fatigue)? }\end{array}$} \\
\hline Yes & $26(86.7)$ & $56(86.2)$ & $4(57.1)$ & 10(100) & 15(88.2) & $6(100)$ & $47(83.9)$ & \multirow[t]{2}{*}{-} \\
\hline No & 4(13.3) & $9(13.8)$ & $3(42.9)$ & - & 2(11.8) & - & $9(16.1)$ & \\
\hline \multicolumn{9}{|c|}{ Are there people with subclinical (mild) symptoms among the patients infected by the Coronavirus? } \\
\hline Yes & $29(96.7)$ & $50(76.9)$ & 7(100) & 10(100) & $17(100)$ & $5(83.3)$ & $43(76.8)$ & \multirow[t]{2}{*}{$<0.001$} \\
\hline No & $1(3.3)$ & 15(23.1) & - & - & - & 1(16.7) & 13(23.2) & \\
\hline \multicolumn{9}{|c|}{ Does Coronavirus have more severe symptoms in people with underlying diseases (diabetes, cancer, high blood pressure, etc.)? } \\
\hline Yes & $30(100)$ & $65(100)$ & $7(100)$ & $10(100)$ & $17(100)$ & $6(100)$ & $54(96.4)$ & \multirow[t]{2}{*}{-} \\
\hline No & - & - & - & - & - & - & 2(3.6) & \\
\hline \multicolumn{9}{|c|}{ Can people with mild symptoms transmit the disease to other people during the incubation period? } \\
\hline Yes & $29(96.7)$ & $62(95.4)$ & $7(100)$ & $10(100)$ & $15(88.2)$ & $5(83.3)$ & $50(89.3)$ & \multirow[t]{2}{*}{-} \\
\hline No & $1(3.3)$ & $3(4.6)$ & - & - & 2(11.8) & $1(16.7)$ & 6(10.7) & \\
\hline \multicolumn{9}{|c|}{ Are people with severe symptoms the only one who cantransmit the disease to others? } \\
\hline Yes & 27(90) & 61(93.8) & $7(100)$ & 10(100) & 15(88.2) & $5(83.3)$ & $54(96.4)$ & \multirow[t]{2}{*}{-} \\
\hline No & 3) 10( & $4(6.2)$ & - & - & 2(11.8) & 1(16.7) & $2(3.6)$ & \\
\hline \multicolumn{9}{|c|}{ Is taking antibiotics effective in preventing or treating the Coronavirus? } \\
\hline Yes & $2(6.7)$ & $12(18.5)$ & $1(14.3)$ & - & $2(11.8)$ & - & $12(21.4)$ & \multirow[t]{2}{*}{-} \\
\hline No & 28(93.3) & $53(81.5)$ & $6(85.7)$ & $10(100)$ & 15(88.2) & $6(100)$ & $44(78.6)$ & \\
\hline
\end{tabular}

\section{Health care workers' (HCWs) attitudes toward Coronavirus}

Generally $73.3 \%$ of the health care workers (HCWs) had the attitude that during the epidemic of Coronavirus disease, they should refrain from smoking, wearing multiple masks and arbitrary use of antibiotics. In the meantime, $40 \%$ of physicians were of the opinion that during the epidemic of the disease, one should only avoid arbitrary use of antibiotics. HCWs' attitudes toward self-care and prevention of disease transmission differed when facing patients with mild symptoms and severe symptoms. In fact, there was a significant difference between participants' responses, which means that HCWs observed protective and preventive measures only when they were facing patients with severe symptoms $(P<0.001)$.

There was a significant difference in the participants' responses to the question of whether they considered a baby girl with symptoms of shortness of breath and symptoms similar to the cold to be suspected of having the coronavirus at the time of the epidemic. Thus, $56.9 \%$ of nurses and $80.4 \%$ of HCWs did not consider an individual with such symptoms to be suspected of having the Coronavirus. But in the next question, 60 percent of all HCWs in the study considered a boy with respiratory symptoms and changes in radiological images to be suspected of having the Coronavirus over the past 14 days at the time of the epidemic. There was also a significant difference between the attitudes of HCWs towards the fact that people under the age of 18 have fewer symptoms (Table 3). 
Table 3

Health care workers' (HCWs) attitudes toward Coronavirus

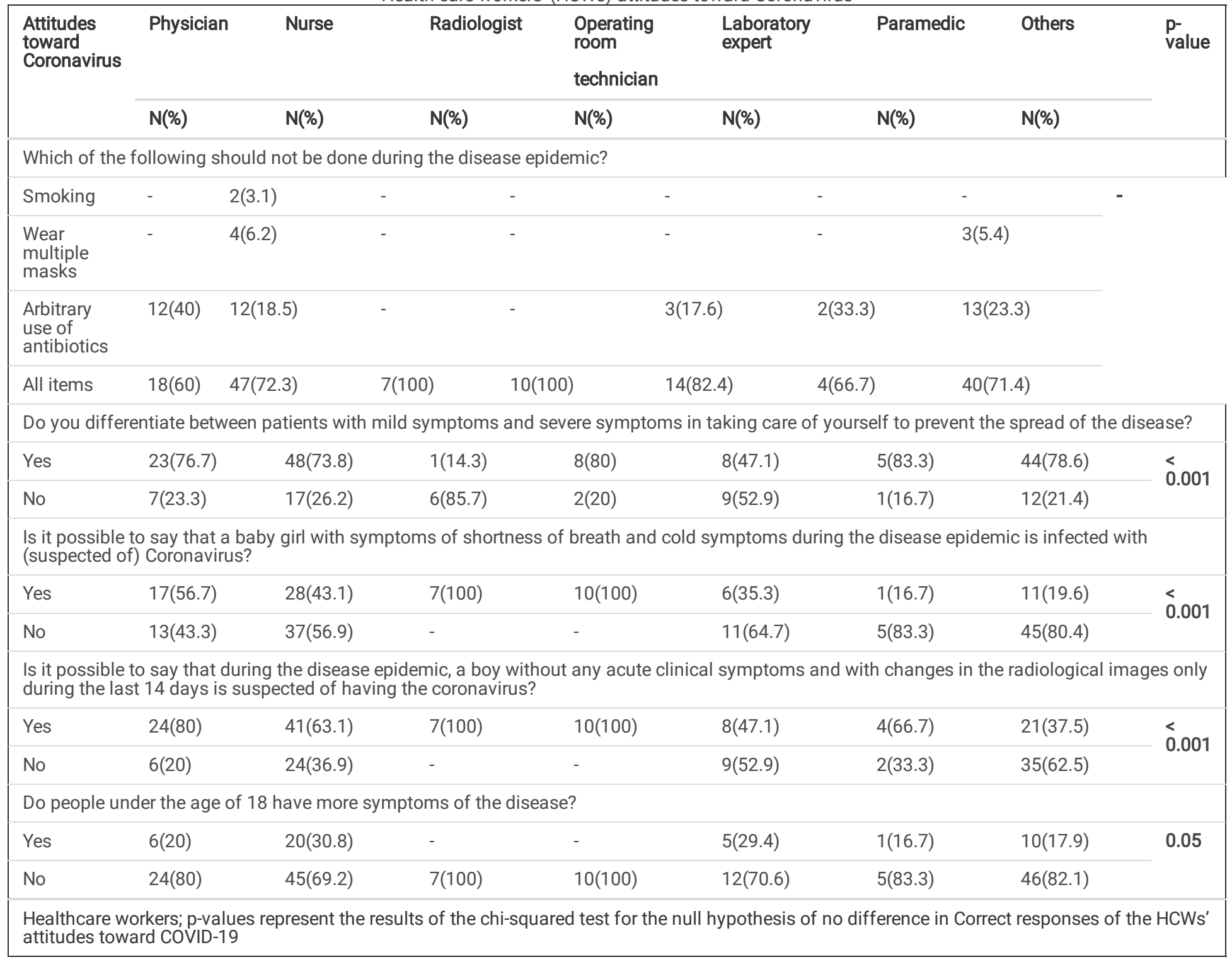

\section{Health care workers' (HCWs) behavior toward Coronavirus}

The results obtained from the evaluation of health care workers' behavior in this study showed that the participants (93\%), especially the medical staff, knew how to use fact masks correctly and most of the HCWs wore surgical masks. Physicians (67\%), nurses (24\%), and operating room staff (100\%) did not keep a1-meter distance from patients (Table 4). 
Table 4

Health care workers' (HCWs) behavior toward Coronavirus

\begin{tabular}{|c|c|c|c|c|c|c|c|c|}
\hline \multirow[t]{2}{*}{ Behavior toward Coronavirus } & Physician & Nursing & Radiologist & $\begin{array}{l}\text { Operating } \\
\text { room } \\
\text { technician }\end{array}$ & $\begin{array}{l}\text { Laboratory } \\
\text { expert }\end{array}$ & Paramedic & Others & \multirow[t]{2}{*}{$\begin{array}{l}\text { p- } \\
\text { value }\end{array}$} \\
\hline & $N(\%)$ & $N(\%)$ & $N(\%)$ & $N(\%)$ & $N(\%)$ & $N(\%)$ & $N(\%)$ & \\
\hline \multicolumn{9}{|c|}{ Do you wash and disinfect your hands after contact with each patient? } \\
\hline Yes & 28(93.3) & $61(93.8)$ & $7(100)$ & 10(100) & $17(100)$ & $6(100)$ & $54(96.4)$ & \multirow[t]{2}{*}{-} \\
\hline No & $2(6.7)$ & $4(6.2)$ & - & - & - & - & $2(3.6)$ & \\
\hline \multicolumn{9}{|c|}{ Do you know how to wear face masks the right way? } \\
\hline Yes & 29(96.7) & $63(96.9)$ & $4(57.1)$ & $10(100)$ & 14(82.4) & $6(100)$ & $53(94.6)$ & \multirow[t]{2}{*}{-} \\
\hline No & $1(3.3)$ & $2(3.1)$ & $3(42.9)$ & - & $3(17.6)$ & - & $3(5.4)$ & \\
\hline \multicolumn{9}{|c|}{ Do you use a surgical mask in the workplace? } \\
\hline Yes & $29(96.7)$ & $43(66.2)$ & $7(100)$ & $10(100)$ & $5(29.4)$ & $1(16.7)$ & $28(50)$ & \multirow{2}{*}{$<.001$} \\
\hline No & 1(3.3) & 22(33.8) & - & - & 12(70.6) & 5(83.3) & $28(50)$ & \\
\hline \multicolumn{9}{|c|}{ Do you use a filtered mask (N95) in the workplace? } \\
\hline Yes & $4(13.3)$ & 21(32.3) & $6(85.7)$ & - & $6(35.3)$ & $4(66.7)$ & $9(16.1)$ & \multirow{2}{*}{$<.001$} \\
\hline No & 26(86.7) & $44(67.7)$ & $1(14.3)$ & 10(100) & 11(64.7) & 2(33.3) & 47(83.9) & \\
\hline \multicolumn{9}{|c|}{ Do you keep the distance (at least one meter) during contact with the patient? } \\
\hline Yes & $7(23.3)$ & $48(73.8)$ & $4(57.1)$ & - & $8(47.1)$ & $4(66.7)$ & 44(78.6) & \multirow{2}{*}{$\langle .001$} \\
\hline No & 23(67.7) & 16(24.6) & $3(42.9)$ & 10(100) & $7(41.2)$ & 2(33.3) & 12(21.4) & \\
\hline \multicolumn{9}{|c|}{ Do you adhere to the above principles only in the face of patients with severe symptoms or patients with mild symptoms as well? } \\
\hline $\begin{array}{l}\text { Only for patients with severe } \\
\text { symptoms }\end{array}$ & $1(3.3)$ & $9(13.8)$ & - & $4(40)$ & - & - & $9(16.1)$ & \multirow[t]{2}{*}{0.05} \\
\hline Only for patients with mild symptoms & $3(10)$ & $6(9.2)$ & - & - & $2(11.8)$ & - & $1(1.8)$ & \\
\hline In both cases & $26(86.7)$ & $47(72.3)$ & $7(100)$ & $6(60)$ & 15(88.2) & $6(100)$ & $40(71.4)$ & \\
\hline $\begin{array}{l}\text { There is no need to adhere to the } \\
\text { above principles }\end{array}$ & - & $3(4.6)$ & - & - & - & - & $6(10.7)$ & \\
\hline
\end{tabular}

\section{Discussion}

Important results of this study were the lack of awareness of health care workers (HCWs) about the presence of a patient with mild symptoms as well as the ability of disease transmission in suspected or subclinical patients. For this reason, some health care workers facing these people did not apply the preventive measures designed to limit the transmission of the disease from suspected patients to other patients and even to themselves, indicating a lack of knowledge and attitude of the health care workers about the disease. But in contrast, they considered a person with symptoms of shortness of breath and changes in radiological images to be suspected of having COVID-19over the past 14 days at the time of the epidemic. The evaluation of HCWs' behavior in this study showed that unfortunately most of HCWs in Taleghani hospital, due to the nature of their work were not able to keep a one-meter distance from patients, which can infect them and transmit the virus. With regards to the nature of COVID-19 which is a new virus with a very rapid epidemic associated with mortality [12], such attitude and behavior is very harmful.

Inadequate personal protection before starting work and during the treatment of patients at the onset of the epidemic period of the disease can be cited as reasons for the health care workers becoming infected with the Coronavirus. This behavior was due to a lack of knowledge and awareness 
about the level of virulence of the SARS-CoV-2. The second reason for the health care workers becoming infected was the prolonged exposure to the infected environment and proximity to patients infected by the virus, which increases the risk of infection in HCWs [13]. At the onset of the epidemic period of the disease in China, 15 health care workers were affected by COVID-19, which rose to 1,716 by February 11, 2020 [14].

Other problems of HCWs in the present study were the shortage in providing medical equipment such as N95 masks, disposable clothing, goggles, gloves, etc. Lack of this equipment itself can transmit the virus and infect the health care workers. However, this problem did not only exist in Iran but also was mentioned by Wang et al. [15] in a study in China. Other hidden factors that increased the incidence of the disease were factors such as fear of being infected with the disease and its transmission to the family, severity of work, and lack of adequate rest [15]. In the present study, about $92 \%$ of the WHCs were afraid of being infected with the disease and transmitting it to the family. Stress, as a hidden variable, indirectly weakens the immune system and increases the risk of disease [16]. Due to the novelty of the virus and its rapid epidemic, health care workers did not receive adequate training and awareness regarding the prevention and control of COVID-19. For example, they should be aware of behaving in the same way when dealing with subclinical and acute cases, because subclinical cases can also transmit the infection. But, in the present study, health care workers did not distinguish between these two cases and did not consider the subclinical cases as the infected ones, which in turn can increase the risk of infection among health care workers. This result is consistent with the results of the study by Chang et al. [5]. The effect of lack of awareness on infection prevention and control for COVID-19 and increased risk of disease in WHCs were mentioned in both studies. Respiratory infections such as Quaid 19 in healthcare personnel, despite having sufficient knowledge and awareness of self-care against respiratory infectious diseases due to lack of attention and imperfect behavior towards preventive recommendations and protective standards it may be created [17].

\section{Conclusion}

Knowledge, attitude, and behavior toward COVID-19 infection and facing patients with severe and overt symptoms among health care workers in the hospital were excellent, but these were insufficient for people without obvious symptoms. These results suggest that additional training in subclinical cases of Coronavirus is needed for health care workers to protect them from contamination and prevent disease transmission to their colleagues and other patients as well. Also, without any distinction, health care workers should be trained on how to use protective devices and observe protective behaviors when facing any person infectedbyCOVID-19, whether with clinical or subclinical symptoms, and their behaviors should be followed up in this regard as well. Finally, considering the fear and stress caused by this disease, it is suggested that psychological counseling be carried out to overcome the fear and stress caused by disease transmission in the health care workers at the onset of and during these epidemics.

\section{Abbreviations}

Health care workers (HCWs); Standard deviation (SD); Number (N).

\section{Declarations}

\section{Acknowledgments}

The authors thanks health care workers (HCWs) at the Kermanshah University of Medical Sciences for their participation in this survey.

\section{Authors 'contributions}

NM, MS, FK and FM conceived and designed the study protocol. NM, MS and HF collected the data. NM, MS and NF were involved in the analysis. NM, MS and NF wrote the first draft of the manuscript. FK, FM, NF and HF reviewed and revised the manuscript and produced the final version. All authors have read and approved the final manuscript.

\section{Funding}

No funding was received for the study.

\section{Availability of data and materials}

The data sets used and/or analyzed during the current study are available from the corresponding author on reasonable request.

\section{Ethics approval and consent to participate}

The study has received ethical approval from Ethics Review Committee (ERC), Kermanshah University of Medical Sciences (IR.KUMS.REC.1399.031). Also, approval (verbal and written) has been obtained from the participants in study.

\section{Consent for publication}

Not applicable

\section{Competing interests}


The authors declare that they have no competing interests

\section{Author details}

1. Clinical Research Development Centre, Taleghani and Imam Ali Hospital, Kermanshah University of Medical Sciences, Kermanshah, I.R. Iran. ${ }^{2}$ Research Center for Environmental Determinants of Health, Health Institute, Kermanshah University of Medical Sciences, Kermanshah, Iran. ${ }^{3 .}$ Clinical Research Development Centre, Imam Khomeini, Mohammad Kermanshahi and Farabi Hospital, Kermanshah University of Medical Sciences, Kermanshah, I.R. Iran.

\section{References}

1. Hall AJ, Tokars JI, Badreddine SA, Saad ZB, Furukawa E, Al Masri M, et al., Health care worker contact with MERS patient, Saudi Arabia. Emerg Infect Dis. 2014;20(12):2148-51. http://dx.doi.org/10.3201/eid2012.141211

2. Reuss A, Litterst A, Drosten C, Seilmaier M, Böhmer M, Graf P, et al. Contact investigation for imported case of Middle East respiratory syndrome, Germany. Emerg Infect Dis. 2014;20(4):620-5. http://dx.doi.org/10.3201/eid2004.131375.

3. Bogoch II, Watts A, Thomas-Bachli A, Huber C, Kraemer MUG, Khan K. Potential for global spread of a novel coronavirus from China. J Travel Med. 2020;27(2) http://dx.doi.org/10.1093/jtm/taaa011.

4. Tuite AR, Bogoch II, Sherbo R, Watts A, Fisman D, Khan K. Estimation of COVID-2019 burden and potential for international dissemination of infection from Iran. Ann Intern Med. 2020. http://dx.doi.org/10.7326/M20-0696.

5. Chang, Xu H, Rebaza A, Sharma L, Dela Cruz CS. Protecting health-care workers from subclinical coronavirus infection. Lancet Respir Med. 2020;8(3):e13. http://dx.doi.org/10.1016/S2213-2600(20)30066-7.

6. Chan JF, Yuan S, Kok KH, To KK, Chu H, Yang J, et al. A familial cluster of pneumonia associated with the 2019 novel coronavirus indicating person-to-person transmission: a study of a family cluster. Lancet. 2020;395(10223):514-523. http://dx.doi.org/10.1016/S0140-6736(20)30154-9

7. Kim TH. Institutional preparedness for infectious diseases and improving care. JKMA. 2015;58(7):606-610. http://dx.doi.org/10.5124/jkma. 2015.58.7.606.

8. Memish ZA, Zumla Al, Assiri A. Middle East respiratory syndrome coronavirus infections in health care workers. N Engl J Med. 2013. 369(9):884886. http://dx.doi.org/10.1056/NEJMc1308698.

9. China National Health Commission.Announcement of national health commision of the people's republic of China. Jan 20, 2020. accessed Feb 6, 2020: http://wwwnhcgovcn/jkj/s7916/202001/44a3b8245e8049d2837a4f27529cd386shtml

10. Alsahafi AJ1, Cheng AC. Knowledge, attitudes and behaviours of healthcare workers in the Kingdom of Saudi Arabia to MERS coronavirus and other emerging infectious diseases. Int J Environ Res Public Health. 2016;13(12):1214. http://dx.doi.org/10.3390/ijerph13121214.

11. Lan L, Xu D, Ye G, Xia C, Wang S, Li Y, Xu H. Positive RT-PCR Test Results in Patients Recovered From COVID-19. JAMA. 2020: http://dx.doi.org/10.1001/jama.2020.2783.

12. Ahmadzadeh J, Mobaraki K, Mousavi SJ, Aghazadeh-Attari J, Mirza-Aghazadeh-Attari M, Mohebbi I. The risk factors associated with MERS-CoV patient fatality: A global survey. Diagn Microbiol Infect Dis. 2020;96(3):114876. http://dx.doi.org/10.1016/j.diagmicrobio.2019

13. Wu, A., et al., Novel coronavirus (2019-nCov) pneumonia in medical institutions: problems in prevention and control. Chin J Infect Control, 2020. 19: p. 1-6.

14. Ran L, Chen X, Wang Y, Wu W, Zhang L, Tan X. Risk Factors of Healthcare Workers with Corona Virus Disease 2019: A Retrospective Cohort Study in a Designated Hospital of Wuhan in China. Clin Infect Dis. 2020. http://dx.doi.org/10.1093/cid/ciaa287

15. Wang $\mathrm{J}^{1}$, Zhou $\mathrm{M}^{2}$, Liu F. Reasons for healthcare workers becoming infected with novel coronavirus disease 2019 (COVID-19) in China. J Hosp Infect. 2020. http://dx.doi.org/10.1016/j.jhin.2020.03.002

16. Antoni $\mathrm{MH}^{1}$, Dhabhar FS. The impact of psychosocial stress and stress management on immune responses in patients with cancer. Cancer. 2019;125(9):1417-1431. http://dx.doi.org/10.1002/cncr.31943.

17. Radonovich LJ Jr, Simberkoff MS, Bessesen MT, Brown AC, Cummings DAT, Gaydos CA, et al., N95 Respirators vs Medical Masks for Preventing Influenza Among Health Care Personnel: A Randomized Clinical Trial. JAMA. 2019;322(9):824-833. http://dx.doi.org/10.1001/ jama.2019.11645 